\title{
Environmental impact assessment for city logistics distribution systems
}

\author{
Jidong Guo ${ }^{1}$, Shugang $\mathrm{Ma}^{2+}$ \\ ${ }^{1}$ Department of Economics and Management, Institute of Disaster Prevention Science and Technology, Beijing 101601, China \\ ${ }^{2}$ Business School, Hebei University of Economics and Business, Shijiazhuang, Hebei 050061, China
}

\begin{abstract}
The external diseconomy is hampering sustainable development of the city logistics sector. Burdens on urban environment imposed by the city logistics industry have been put in the spotlight. Based on the principle of Life Cycle Analysis, the comprehensive environment impact for city logistics systems is measured. Firstly, with the city logistics service chain as a whole, its business processes and their interactions with environment are analyzed. In total four types of major environment impact categories are determined. Secondly, case study is made on three city logistics operators located in Jing-Jin-Ji region of China with different business modes, respectively self-operation mode, joint distribution mode and the $3^{\text {rd }}$ Party Logistics or 3PL mode. Through analysis of energy consumption and emissions for various business processes, their comprehensive environmental impact values are finally obtained. Thirdly, horizontally comparative analysis is carried out to these three modes of the urban logistics distribution systems. Results show the advantages of the 3PL and the joint distribution modes in developing greener urban logistics distribution. Future research avenues and policy suggestions are proposed finally.
\end{abstract}

Keywords: Environmental impact, Joint distribution, Life cycle analysis, Urban logistics distribution, 3PL

\section{Introduction}

The acceleration of urbanization in China attracts large numbers of people pouring into cities. With the development of urban economy and the improvement of people's living standard, commercial chain business and e-commerce are flourishing in urban areas. As a result, city logistics sector has experienced unprecedented rapid growth in the past decade. City logistics plays an important role in improving economy vitality in urban areas [1]. However, Hirohito et al. doubt the purely economic benefit-oriented development mode of city logistics [2]. Its social and environmental effect could not be overlooked, too. According to a report issued by the Asian Development Bank, among the top 10 most polluted cities around the world, 7 are located in China [3], particularly in the economic zone surrounding Beijing. Within China, the top 7 cities with the heaviest air pollution lie also in the zone. City logistics industry contributes a lot to energy consumption and pollutant emission within cities, as poses a huge challenge to urban sustainable development. Besides its competition with public or private sectors for urban scarce resources such as land, street and arteries, city logistics contributes significantly to city traffic congestion and environmental nuisances [4]. An OECD report attributes $43 \%$ of sulfur oxides, $61 \%$ of particle matter emissions in London, 50\% in Prague and 77\% in Tokyo of nitrogen oxides emissions to city freight transportation [5]. Therefore, it requires a comprehensive assessment of environmental impact for different city logistics distribution systems, so as to gain an insight into the key factors causing environmental problems, and further propose targeted solutions.

Life Cycle Assessment, as a standard process to evaluate energy consumption and environment load for products, processes or activities, has widely been used for different sectors. For example, Norgate et al. evaluate the carbon footprint for gold production with different raw ores and exaction processes [6]. Mcauliffe et al. review pig production Life Cycle Analysis (LCA) at different stages and suggest several key targets in improving its environmental performance [7]. Considerable efforts have been made to apply LCA to tangible products and the manufacturing processes, but the environmental impact of services has drawn lower attentions to date. An exception is that Christophe develops a process to collect data, measure energy uses and GHG emissions from logistics activities for product supply
This is an Open Access article distributed under the terms of the Creative Commons Attribution Non-Commercial License (http://creativecommons.org/licenses/by-nc/3.0/) which permits unrestricted non-commercial use, distribution, and reproduction in any medium, provided the original work is properly cited.
Received October 5, 2016 Accepted April 22, 2017

${ }^{\dagger}$ Corresponding author

Email: mashugang@126.com

Tel: +86-311-87657308 Fax: +86-311-87657108

Copyright (C) 2017 Korean Society of Environmental Engineers 
chains [8]. Extra research shall be made to evaluate the comprehensive environmental impact of logistics-related activities, not just carbon emissions. Furthermore, emissions may change greatly based on different logistics distribution modes, i.e., self-operation logistics or outsourcing logistics mode. These motivate us to carry out this research.

In this study, energy consumption and emissions for city logistics distribution systems with different operation modes were studied. Based on the LCA method, the business processes for logistics distribution service systems are analyzed. Then a complete inventory of energy consumption and emissions throughout a full service cycle is obtained. Furthermore, four types of environmental impact categories are respectively demonstrated and finally, a comprehensive environmental impact assessment for various city logistics distribution systems is obtained. In real case study, by comparing totally 3 different types of city logistics distribution modes, namely, the third-party logistics mode, the joint distribution mode and self-operation mode, it proves the superior environmental management capacity for the joint distribution mode and the third-party logistics mode. The conclusions could help city managers and practitioners to improve the logistics industry development planning and improve the green operation ability of urban logistics services. Future research suggestions are also proposed.

\section{LCA-based Assessment Method for City Logistics Distribution Systems}

The mail objective of this research is to obtain the comprehensive environmental impact values for typical city logistics distribution systems servicing urban commercial chain firms. The surveyed companies are all regional market leaders involved in operating networked department stores, supermarkets and/or corner stores. Due to differentiated temperature and tolerance requirements for different products, various types of transport vehicles and distribution centers are used in city logistics distribution systems, such as varied vehicles using diesel, gasoline, electricity or natural gas as fuels, different vehicles and distribution centers for normal temperature, low temperature or even ultra-low temperature storage and transportation, etc. Business processes of such complex city logistics systems need to be decomposed and/or recomposed so as to facilitate energy consumption data collection for surveyed companies involved. The basic evaluation process includes four steps, i.e., goal and scope definition, life cycle inventory analysis, life cycle impact assessment and life cycle report.

\subsection{Goal and Scope Definition}

To satisfy consumers' demands, city logistics distribution service system, with distribution centers located in city centers or suburban areas as its critical infrastructure, logistics operators are responsible to collect goods from outside of cities or outer suburbs, then after a series of processing activities within the distribution centers and ship them to destined customers. Of course, the goal of this study is to obtain the comprehensive environment impact for above city logistics distribution service systems. They involve a couple of actors and facilities, such as suppliers, warehouses, distribution centers, retailers and service integration operators, etc. The specific business processes include goods collection, loading and unloading, storage, transit, distribution, re-processing, normal or cold storage and transportation, selecting and picking, etc., which, obviously, are complex multi-user, multi-process systems. Since city manufacturing function declines currently, a commonly seen city logistics distribution model is studied. That is to say, product manufacturers send their goods to logistics centers in outer suburbs, then waiting for the end-users' orders. According to users' demands, proper goods are sent to specified distribution centers, where selecting, picking-up, distribution processing, and packaging work will be done. Finally, goods would be transported to the various sales terminals. In this way, the research scope is defined on such a standard network logistics system from logistics centers via distribution centers to sales terminals.

\subsection{Lifecycle Inventory Analysis}

This is the most critical step in the implementation of life cycle analysis. By analyzing energy consumption and emissions discharge for different business processes of the city logistics distribution systems, meanwhile taking the related data availability into account, the raw data of energy consumption and pollutant discharge are obtained [9]. Other tasks at this step also include data validation check, association quantification between data, etc.

According to the border of the city logistics distribution system determined in the first subsection, the analysis framework of system material input and output could be given as the Fig. 1. It could also be seen that the figure is actually in accordance with the operational management process of city logistics distribution system. The framework considers both direct and indirect energy consumption, and emissions in the system, including the fuel consumption of different business processes, such as diesel, gasoline, compressed natural gas, liquefied petroleum gas, etc., and a variety of waste and emissions, including carbon dioxide, toxic and harmful gases and fine particles, etc. Besides, in this figure, it also considers

Table 1. Analysis of Environmental Impact Inventory for City Logistics Distribution Systems

\begin{tabular}{|c|c|c|c|}
\hline \multicolumn{2}{|r|}{ Business process } & \multirow{2}{*}{$\begin{array}{c}\text { Energy consumed } \\
\text { Gasoline, Diesel, Compressed Natural Gas, } \\
\text { Liquefied Petroleum Gas, Electricity }\end{array}$} & \multirow{2}{*}{$\frac{\text { Emissions }}{\mathrm{HC}, \mathrm{CO}_{2}, \mathrm{CO}, \mathrm{SO}_{2}, \mathrm{NO}_{\mathrm{x}}, \mathrm{PM}}$} \\
\hline Freight & Transit Transport & & \\
\hline \multirow{4}{*}{$\begin{array}{l}\text { Distribution } \\
\text { Centers }\end{array}$} & Loading and Unloading, Handling & Gasoline, Diesel, Electricity & $\mathrm{HC}, \mathrm{CO}_{2}, \mathrm{CO}, \mathrm{NO}_{\mathrm{x}}, \mathrm{PM}, \mathrm{SO}_{2}$ \\
\hline & $\begin{array}{c}\text { Storage (Including Refrigeration, Frosting), } \\
\text { Heating }\end{array}$ & $\begin{array}{l}\text { Electricity, Outside Energy Source for } \\
\text { Heating and Cooling }\end{array}$ & $\mathrm{HC}, \mathrm{CO}_{2}, \mathrm{CO}, \mathrm{NO}_{\mathrm{x}}, \mathrm{PM}, \mathrm{SO}_{2}$ \\
\hline & Reprocessing & Gasoline, Diesel, Electricity & $\mathrm{HC}, \mathrm{CO}_{2}, \mathrm{CO}, \mathrm{NO}_{\mathrm{x}}, \mathrm{PM}, \mathrm{SO}_{2}$ \\
\hline & Selecting, Picking-up, Packaging & Electricity & $\mathrm{CO}_{2}, \mathrm{NO}_{\mathrm{x}}, \mathrm{PM}, \mathrm{SO}_{2}$ \\
\hline
\end{tabular}




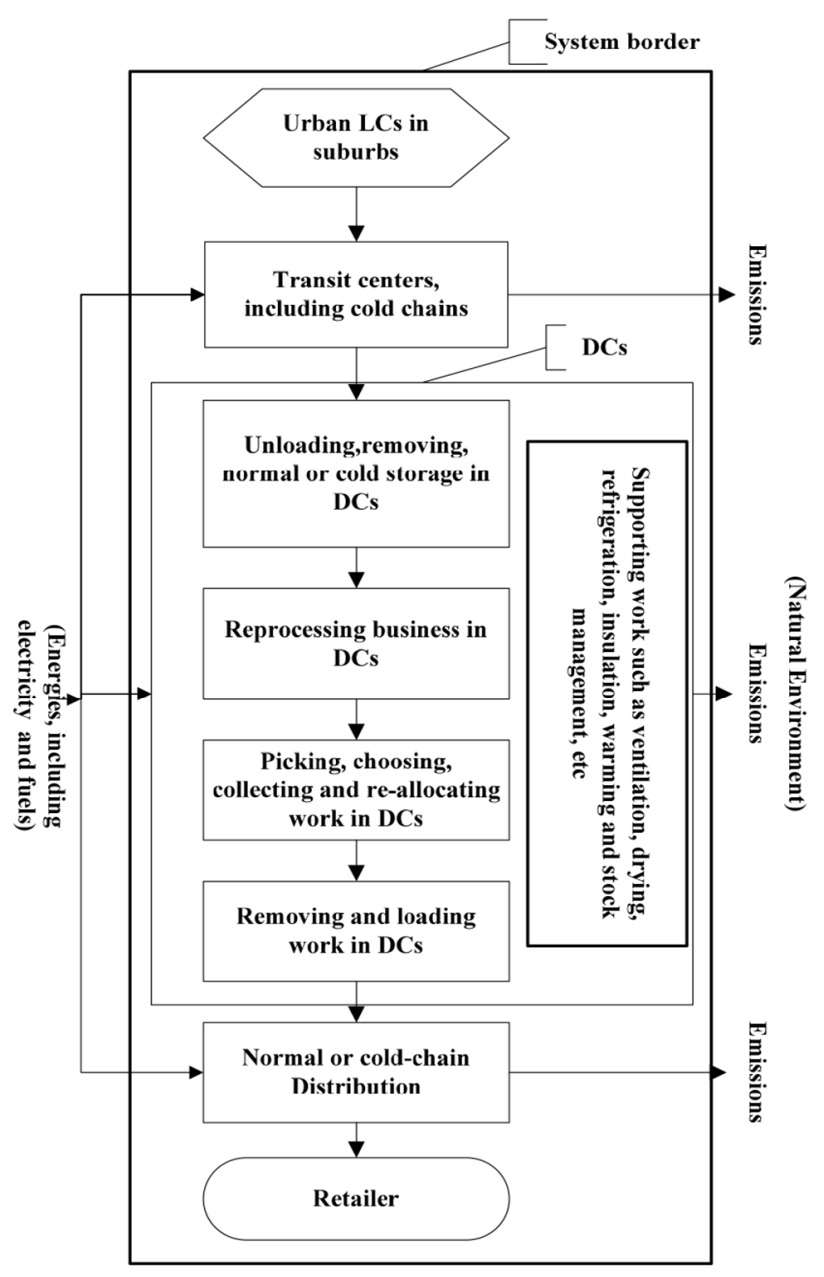

Notes:

LCs-logistics centers DCs-distribution centers

Fig. 1. Framework of material analysis for city logistics distribution system.

the fuel and power consumption in handling forklifts, cranes, processing equipment within the distribution centers, as well as the electric power consumption during the process of storage, and indirect discharge of pollutants from power, cold or hot water supply.

At this stage, various fuels or indirect energies are consumed to give out much different but a large amount of emissions. Moreover, the amount of emissions is extremely uncertain, affected by the combination of fuel quality, condition, road condition and various load factors. The reasonable simplification is necessary. According to related China's national emission standards, vehicle fuel emissions of $\mathrm{HC}, \mathrm{CO}_{2}, \mathrm{CO}, \mathrm{NO}_{\mathrm{x}}$ and particle matter (PM) influence the environment greatly, while electricity influences the environment through its major emissions such as $\mathrm{CO}_{2}, \mathrm{NO}_{\mathrm{x}}, \mathrm{PM}$ and $\mathrm{SO}_{2}$. The exact amount of these emissions could be calculated according to the threshold values set in the related China's national standards. The emission factors of $\mathrm{CO}_{2}$ for various fuels and power could be referred in the official statistics [10-11]. The Table 1 lists the emission inventory of main resources, fuels, indirect energies and major emissions for the city logistics distribution system.

\subsection{Lifecycle Impact Assessment}

The international community has reached a consensus on categories of environmental impacts, the key emissions causing environmental impacts, the affected scope for various categories and category parameters. In total 6 categories for environmental impact of different emissions will be considered, which include Greenhouse Warming Potential (GWP), Acidification Potential (AP), Ozone Depleting Potential (ODP), Ecology Toxicity Potential (ETP), Photochemical Ozone Creation Potential (POCP) and Human Toxicity Potential (HTP) [12]. Taking the emission types of city logistics distribution systems into account, in this study, 4 major impact categories will be discussed, which are illustrated in the following Table 2.

First of all, in the Table 2, the emissions are grouped by the 4 environmental impact categories mentioned at the subsection 2. Secondly, according to category parameters [12] recommended by the Intergovernmental Panel on Climate Change, the various feature values of environmental impact categories, expressed as unit kg equivalent, could be deduced. Additionally, by normalizing the feature values of 4 environmental impact categories, feature values will be divided by the internationally recommended normalization values, with unit of kg equivalent per year [12]. Finally, the weighted sum of normalized values can induce unique comprehensive environmental impact values for each city logistics distribution systems, with unit of years, which can be compared vertically and horizontally. At the final procedure of weighted sum, weight factors are obtained subjectively, which would be different depending on the different countries, regions, cities or different industries. In this study, several experts from environmental protection field are invited to judge these weight factors. The importance of environmental impact categories is compared respectively to acquire needed judgment matrix. If satisfying the consistency on the matrix, the eigenvectors of judgment matrix are deduced and are normalized. The normalized eigenvectors are the weights corresponding to the 4 environmental impact categories.

\subsection{Lifecycle Interpretation and Report}

Work at this step is mainly composed of analysis and explanation

Table 2. Environmental Impact Categories and Loading Items for City Logistics Distribution System

\begin{tabular}{cccc}
\hline Environmental impact category & Environmental loading items & Affected scope & Category parameter \\
GWP & $\mathrm{CO}_{2}, \mathrm{HC}\left(\mathrm{CH}_{4}\right.$ Unit $)$ & Global & kg $\mathrm{CO}_{2}$ Equivalent \\
$\mathrm{AP}$ & $\mathrm{SO}_{2}, \mathrm{NO}_{\mathrm{x}}\left(\mathrm{NO}_{2}\right.$ Unit $)$ & Regional & kg $\mathrm{SO}_{2}$ Equivalent \\
$\mathrm{POCP}$ & $\mathrm{SO}_{2}, \mathrm{NO}_{\mathbf{x}}, \mathrm{CO}$ & Regional & kg Ethylene Equivalent \\
$\mathrm{HTP}$ & $\mathrm{SO}_{2}, \mathrm{NO}_{\mathrm{x}}, \mathrm{PM}$ & Local & $\mathrm{kg}$ 1,4-Dichlorobenzene Equivalent
\end{tabular}


of the results got in the stage 3 , as well as proposing suggestions and countermeasures. Through the analysis and comparisons at the stage 1 to 3 for different city logistics distribution systems, it can demonstrate the environment impact intensity from different environmental impact categories for an individual system, as well as the key environmental loading items. As a result, environmental performance can be improved by taking pertinent measures deduced from above analysis. In addition, the horizontal comparison of the overall environment impact for different systems and the vertical comparison of environmental impact in the course of the system evolution could also be implemented, which help setting up the industry benchmarking, and improving the environmental management capacity of city logistics distribution system.

\section{Case Description and Data}

In this section, the comprehensive environment impact of three city logistics distribution systems for urban chain store business in Jing-Jin-Ji are is studied. The 3 logistics operators belong to 3 different operation modes respectively, namely, logistics enterprises self-operation mode, joint distribution mode across enterprises and the third-party logistics operation mode. We trace and collect commercial mileage data, fuel and energy consumption data for different types of vehicles, and direct, indirect fuel, energy consumption data within distribution centers for the whole year of 2015.

We use system 1 to 3 to indicate these 3 logistics operators or business modes. They are all retail market leaders in Jin-Jin-Ji region. Among them, the system 1 manages its own huge retail outlet network. The system 2 and 3 are independent logistics service providers offer services to several different large commercial retailers. Their respective service networks could be seen in the
Table 3 below. In addition to different service objects, the 3 systems also own very different freight sheets and transfer warehouses or distribution centers. The following Table 4 shows them in detail.

It is easy to get energy and fuel consumption data within various types of transfer warehouses and distribution centers.

However, it is not easy to follow fuel or electricity consumption related to freight fleets. We turn to collect their mileage data for each type of vehicles. By consulting their average mileage fuel consumption data, it is still safe to get basically accurate total fuel consumption data. Results and analysis are given in the next section based on these data.

\section{Results and Discussion}

According to the standard procedure of the life cycle analysis, it could deduce the characterization results of system environment impact, illustrated in the Fig. 2. Obviously, carbon emissions of city logistics distribution system are the most significant, tens or even hundreds higher than other emissions. That also means greater potential for carbon emission reduction. The larger scale for different logistics distribution systems, the greater effects of Greenhouse Warming Potential, Acidification Potential and Photochemical Ozone Creation Potential. However, through the data analysis, the third party logistics mode applies more professional operation mode, and adopts more standard equipment and facilities. Therefore, compared with the other 2 systems, there are more diesel truck tools applied in transport links, and more hybrid and natural gas power transportation in the distribution process. As a result, the third-party logistics mode could lead to smaller environmental impact and less harm to local city human health than the other two modes of logistics systems. This also indicates that the more use of clean fuels can benefit the environmental performance of the city logistics distribution systems.

Table 3. Logistics Service Network for Different Logistics Operators

\begin{tabular}{|c|c|c|c|c|c|c|c|c|c|}
\hline \multirow[b]{2}{*}{ Distribution network } & \multicolumn{3}{|c|}{ System 1} & \multicolumn{3}{|c|}{ System 2} & \multicolumn{3}{|c|}{ System 3} \\
\hline & Beijing & Tianjin & $\begin{array}{c}\text { Hebei } \\
\text { Province }\end{array}$ & Beijing & Tianjin & $\begin{array}{c}\text { Hebei } \\
\text { Province }\end{array}$ & Beijing & Tianjin & $\begin{array}{c}\text { Hebei } \\
\text { Province }\end{array}$ \\
\hline Department Stores & None & None & None & 16 & 4 & 2 & 7 & 12 & 3 \\
\hline Convenience Stores & 122 & 56 & 5 & 83 & None & None & None & None & None \\
\hline Supermarkets & None & None & None & 16 & 4 & 2 & 28 & 9 & 6 \\
\hline Large Distribution Centers & 1 & 1 & None & 5 & 2 & 2 & 3 & 2 & None \\
\hline Small Transfer Warehouse & 22 & 6 & 2 & None & None & None & 6 & None & None \\
\hline
\end{tabular}

Table 4. Logistics Infrastructure for Different Logistics Operators

\begin{tabular}{ccccccc}
\hline & Infrastructure & Diesel & Gasoline & Electric & Natural gas & Petroleum gas \\
\hline \multirow{2}{*}{ System 1 } & Urban Freight Vehicles & None & 50 & 2 & None & None \\
& Tricycles & None & None & 260 & None & None \\
\hline \multirow{2}{*}{ System 2 } & Pickup Trucks & 22 & None & None & None & None \\
& Urban Freight Vehicles & None & 125 & 36 & 8 & None \\
\hline \multirow{2}{*}{ System 3 } & Pickup Trucks & 26 & None & None & None & None \\
& Urban Freight Vehicles & 54 & 36 & 28 & 6 & 12 \\
\hline
\end{tabular}


Then, the feature values of 4 environmental impact categories are normalized. The normalized results of different city logistics distribution systems are illustrated in the Fig. 3. For the 3 modes of systems, Photochemical Ozone Creation Potential could not be ignored, which account for about $77 \%$ to $79 \%$ of the sum of normalized results respectively. The most direct influence of city logistics distribution system is to the health of the city residents themselves. Its weight in the four indicators given by experts is also the highest, which is also what the local government and residents are most concerned about. In the Fig. 3, the resident health effect of pollutants discharged is the highest for system 2 , then system 1 . The system 3 is the lowest. The reason lies in that more gasoline freight transportation vehicles are applied in the system 2, whereas more environmentally friendly alternative energies are used in the system 3 .

Finally, the Fig. 4 demonstrates the results of the comprehensive LCA. Overall, the scale of city logistics distribution system determines their environmental impact potential, expressed as the Comprehensive Environmental Impact Value (CEIV). It is no doubt that increasing business scale would inevitably lead to the increasing energy consumption and emissions. However, city logistics industry

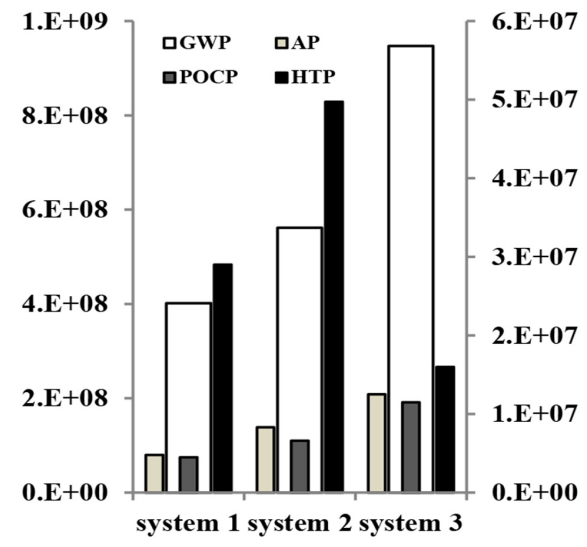

Fig. 2. Characterization results on major impact categories for different city logistics distribution systems(Note: GWP corresponds to the primary axis, the rest to the secondary axis).

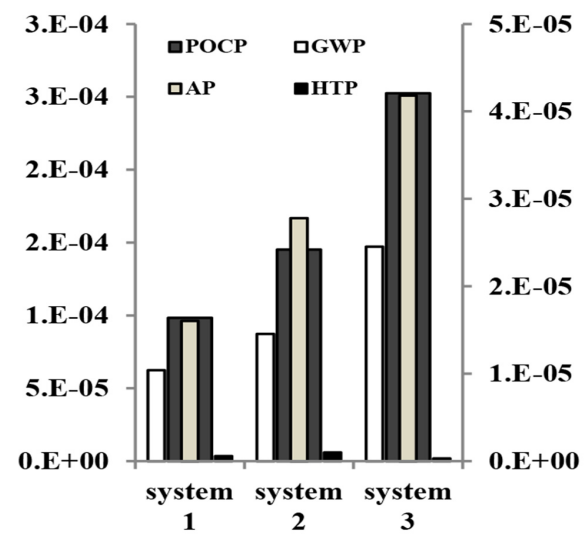

Fig. 3. Normalized comparison of impact categories for different city logistics distribution systems(Note: POCP corresponds to the primary axis, the rest to the secondary axis).

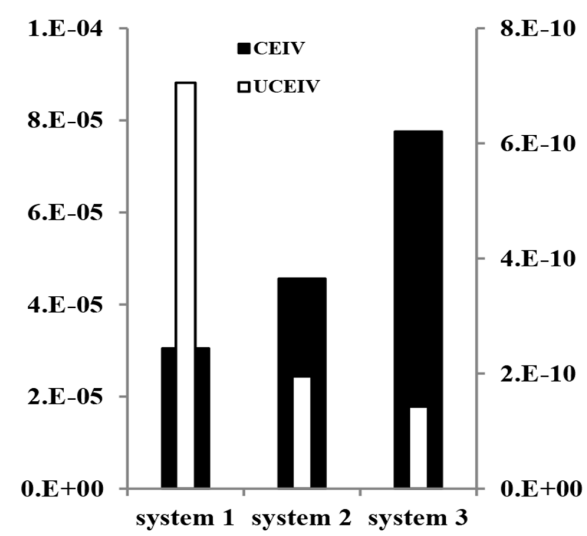

Fig. 4. Comparison of comprehensive impacts for different city logistics distribution systems(Note: CEIV corresponds to the primary axis, UCEIV to the secondary axis).

has obvious scale effect. Out of such consideration, the unit environmental impact, expressed as the Unit Comprehensive Environmental Impact Value (UCEIV), shall be recalculated. It is found that the result is just the opposite to the result of CEIV analysis. The joint distribution mode and the third party logistics operation mode are generally environmental friendly to some extent. Nonetheless, for enterprises' self-operation logistics mode, due to its small scale, its unit environment impact value is 3.6 times and 5 times of respectively compared to the system 2 and 3 . It also confirms the superiority of the above 2 modes in environmental benefits and environmental management.

\section{Conclusions}

City logistics distribution service system plays a fundamental role in promoting the economic development, improving the people's living standards and employment rate within cities. However, burdens to the urban environment it imposes cannot be overlooked.

Through the analysis of city logistics distribution system business process and material balance, a basic framework to evaluate its environmental impact was established. The corresponding evaluation method based on LCA is also constituted. The comprehensive environmental impacts for 3 major distribution system modes were made. Results show that the joint distribution mode and the third-party logistics distribution service mode are able to meet city logistics distribution demands meanwhile with less environmental influence as well as higher operation scale. City authorities shall guide the city logistics mode transitions to greener ones. Meanwhile, reasonable upfront planning for public logistics facilities, road resources and standardization of logistics vehicles shall be made to help emissions reduction of commercial service chains. Moreover, cleaner energy initiatives shall be taken, such as more clean energy sources and higher fuel quality. For city logistics distribution service operators themselves, it is essential for reasonable planning of distribution center layout and key network facility deployment. By strengthening the vehicle routing optimization and vehicle loading rate management, the economic benefits and greater 
environmental benefits could strike a balance at the same time. Meanwhile, greener city logistics will finally benefit city sustainable development.

Of course, cases studied in this article are much limited. More work could be done through investigating a wider range of city logistics operators to help perfecting such a research. Possibly for different regions and different logistics service systems, even with the same operation modes, can yield much different result. Furthermore, due to the nature of LCA itself, sensitivity analysis regarding transitions to cleaner energy, environmental-friendly vehicles and network structure, etc. shall be encouraged in the future.

\section{Acknowledgments}

The authors acknowledge the support from Hebei Province Social Science Foundation Project (Grant No. HB16GL006) and Soft Science Project of Department of Science \& Technology, Hebei Province.

\section{References}

1. Stephen A, Julian A, Michael B. Urban logistics-how can it meet policy makers' sustainable objectiveness? J. Transp. Geogr. 2005;13:71-81.

2. Hirohito K, Akira E, Eiichiro I. Logistics facility, road network and district planning: Establishing comprehensive planning for city logistics. Procedia Soc. Behav. Sci. 2010;2:6251-6263.
3. Zhang QF, Crooks R. Towards an environmentally sustainable future: People's Republic of China national environment analysis. Beijing: China Finance and Economic Press; 2012. p. 54-57.

4. Organisation for Economic Co-operation and Development (OECD). Delivering the goods: 21st century challenges to urban goods transport. OECD Publishing; 2003. p.1-10.

5. Crainic TG, Ricciardi N, Storchi G. Models for evaluating and planning city logistics systems. Transport. Sci. 2009;4:432-454

6. Norgate T, Haque N. Using life cycle assessment to evaluate some environmental impacts of gold production. J. Clean. Prod. 2012;8:53-63.

7. Mcauliffe GA, Chapman DV, Sage CV. A thematic review of life cycle assessment (LCA) applied to pig production. Environ. Impact Assess. Rev. 2016;56:12-22.

8. Christophe R, Eric C, Michael B, Jacques L. GHG emissions of supply chains from different retail systems in Europe. Procedia Soc. Behav. Sci. 2010;3:6154-6164.

9. Guinee JB. Life cycle assessment: An operational guide to the ISO standards. Dordrecht: Kluwer Academic Publishers; 2002. p. 3-47.

10. National Bureau of Statistics of China. China energy statistics. Beijing: China Statistics Press; 2011. p. 341-346.

11. IPCC. IPCC Guidelines for National Greenhouse Gas Inventories. IPCC; 2006. p. 11-41.

12. Penningtona DW, Pottingb J, Finnveden G, et al. Life cycle assessment Part 2: Current impact assessment practice. Environ. Int. 2004;30:721-739. 